\title{
Buccal Route of Administration
}

National Cancer Institute

\section{Source}

National Cancer Institute. Buccal Route of Administration. NCI Thesaurus. Code C38193.

Administration of a substance through the mucosal membrane on the inside of the cheek or the back of the mouth. Buccal route bypasses first pass metabolism and avoids pre-systemic elimination in the gastrointestinal tract. The buccal environment is well supplied with both vascular and lymphatic drainage and is well suited for a retentive device. This is a feasible alternative for systemic delivery of orally inefficient drugs, such as peptide and protein drug molecules. 